\title{
DIFFERENT REINFORCEMENT TECHNIQUES IN DAMAGED BUILDINGS
}

\author{
Altin Bidaj ${ }^{1}$, Enio Deneko ${ }^{2}$, Mario Hysenlliu ${ }^{3}$ \\ ${ }^{1}$ Polytenchnic University of Tirana, Faculty of Civil Engineering, Tirana, Albania \\ altinbidaj@yahoo.com \\ 2 Polytenchnic University of Tirana, Faculty of Civil Engineering, Tirana, Albania \\ eniodeneko@hotmail.com \\ ${ }^{3}$ Polytenchnic University of Tirana, Faculty of Civil Engineering, Tirana, Albania \\ mariohysenlliu@yahoo.com
}

\begin{abstract}
During their lifetime, the capacity of the single elements or of the entire structures is not anymore adequate to the static and dynamic functions requested by the project, mainly caused from deterioration of the masonry structures or the change of the destination and the purpose of the elements. Externally bonded FRP may be used in a repair capacity for structures that have moderate earthquakes damages or to reinforce structures considered to be vulnerable. The FRP strengthening systems are used mainly for flexural and shear strengthening of the structural elements subjected to bending moments and shear forces larger than their flexural and shear capacity, especially the beam-column joints. Many experiences in rehabilitation of damaged masonry buildings have been carried out in Europe in the last decades. Several unsuccessful results have underscored the need for adequate assessment prior to any rehabilitation. In fact, when neither the real state of damage nor the effectiveness of repairs is known, the results of the intervention are also unpredictable. In this article there are described different techniques used for reinforcement of masonry structures, with their advantages or disadvantages.
\end{abstract}

Keywords: masonry structures, FRP systems, joints, reinforcement, replacement, repair

\section{Introduction}

The experience of the last decades in repair, strengthening and the preservation of masonry buildings in historic centers of seismic areas taught us that reinforcement techniques have to be chosen carefully in order to obtain positive results. Several unsuccessful results have become necessary an adequate assessment prior to any restoration or rehabilitation. In fact, when neither the real state of damage nor the effectiveness of repairs is known, the results of the intervention are also unpredictable. This was clearly shown by some repair failure even when advanced materials had been used. Now there is enough information to support the choice of compatible materials and techniques for repair.

In this point, a deep knowledge is needed for the building history and evolution, geometry, structural details, crack pattern, wall construction technique and materials, material properties, structure stability. This knowledge can be reached through visit in situ and laboratory experimental investigation, structural analysis using appropriate models and final diagnosis. Several techniques can be discussed and the optimal one can be chosen from the point of the best intervention compatible with the available budget, but also respecting the safety necessities for the building.

This means that the new materials used for repair and strengthening will be chemically, physically and mechanically compatible. It is impossible to ask that they have to be exactly the same as the original ones. As a consequence of that, repair and improvement will be better than substitution. Today the need for rehabilitation and repair of damaged masonry buildings allows the application and experimentation of both traditional and advanced techniques.

\section{Methodology of interventions}

An important requirement to be considered in the selection of any material or technology used for repair and strengthening is based on the needed compatibility between the new and the original parts. A difficult choice, 
regarding compatibility, is the use of traditional materials and techniques against modern or innovative ones. The first ones are normally compatible to the original parts due to the combination of similar properties.

\subsection{Traditional techniques}

These techniques use traditional methods, materials and tools. They are easy to implement, and can be carried out by companies of small size. Traditional materials, such as lime mortar, have already proven their durability and compatibility with other historical materials across long periods of time. Another advantage of traditional or historical structures is the fact that, having been used historically to improve or strengthen many ancient structures, if implemented now in a heritage structure, does not severely impact on its original character and authenticity. Some relevant ancient techniques, still used nowadays for repair and strengthening, are discussed below.

\section{Local dismantling and reconstruction}

The existing masonry pattern is locally removed where major deterioration has occurred and it is replaced with new masonry reproducing the mechanical properties of the original one. Local dismantling and reconstruction preserves the mechanical efficiency and the continuity in a masonry structure. Local reconstruction can be considered partially reversible, while fully compatible and durable thanks to the use of materials similar to the original ones.

\section{Structural re-pointing}

Consists of the partial, but deep removal of deteriorate mortar in joints and substitution with new mortar (possibly with better mechanical properties and durability). It is partially reversible (if the new mortar can still be removed from the joints) and satisfactorily compatible and durable. Separation or debonding at the mortar interface such as a brick or a stone does not constitute a severe damage and can be easily repaired by just filling the crack with new mortar.
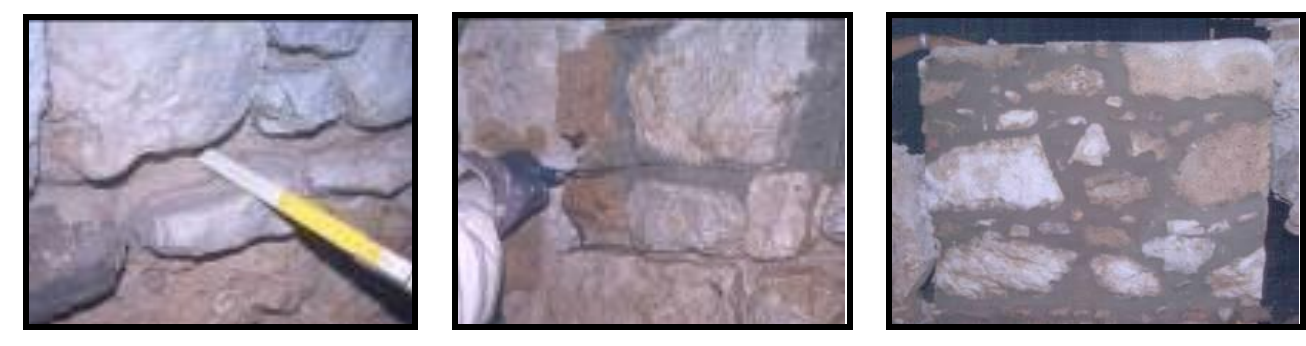

Fig. 1. Grout injection procedure, drilling holes in mortar joints and fixing

The continuous refilling of this type of cracks after soil settlements or other possible actions has been historically a common repair or maintenance practice. If properly executed, the structure recovers its initial material continuity and structural performance. Moreover, the structure can be re-repaired used the same procedure. Cracks affecting bricks or stone blocks are more difficult to repair but can also be treated by the same techniques. Masonry with damaged units has been traditionally repaired by substituting the affected material by new one.

\section{Tying}

Iron or steel bars, anchored with plates or other devices to the structure, have been successfully used in the past to improve the overall structural behavior by ensuring an adequate connection between structural elements. There are different practical applications. Tie bars are non-invasive and can be easily removed. They provide an efficient and durable tying action if their end anchorages are maintained in good condition.

Ties in dwellings, palaces, churches and towers have a traditional character in many countries and have been widely used in both seismic (Italy) and also non-seismic places (Northern Europe). However, when visible (across the arches), their use for modern strengthening may be sensed as "obtrusive" by people. As observed in recent earthquakes, ties show significant mechanical compatibility with masonry structural systems. Ties contribute very satisfactorily to improve the seismic performance of buildings thanks to their mass-less and flexible character, as opposite to alternative solutions such as new stiff concrete floor slabs or roofs. 


\section{Intramural tying}

It means application of punctual confinement to the wall, either with transversal iron or steel bars, anchored to plates or other metal or timber devices on both sides of the wall. The technique avoids leaf separation in the case of walls composed of several leaves, or to avoid internal cracking in the case of walls with poor internal interlocking.

\section{Fastening}

Different blocks or members are tied together by means of stiff devices such as pins and cramps or short ties. It was used in the past to tie together parts with poor connection or interlocking and to prevent from partial failure. Local tying is meant to develop a micro-continuity in the structure thus improving structural connectivity and strength. It constitutes a simple and effective technique, mostly reversible, allowing the increase of the resistance of the element.
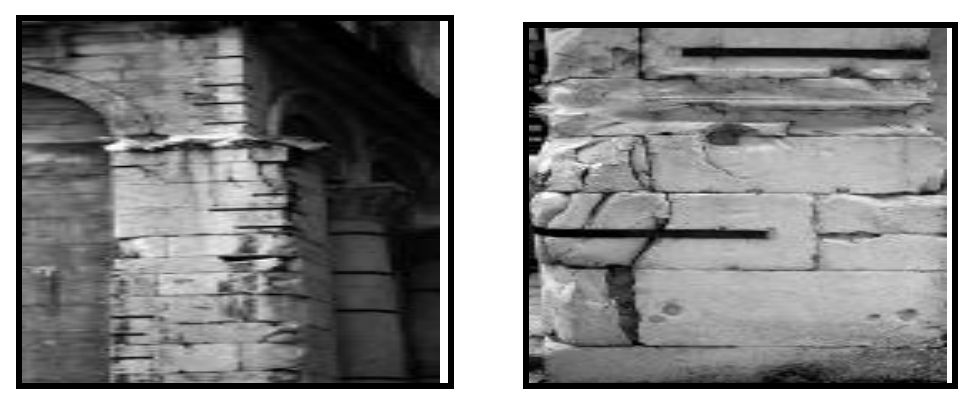

Fig. 2. Crack fastening by metal bars

\section{Confinement of piers by means of stiff rings}

It means application of steel rings in critical sections of the pier to stabilize damaged material or improving the compressive strength, stiffness and ductility of the pier. It is a fully historical and traditional, fully non-invasive and reversible technique characterized by its high effectiveness. However, and while effective for repair and strengthening for gravity loads, this technique may not significantly increase the overall seismic response of a building.

Overall substitution of a structural member

A typical example is overall substitution of floors and roofs when the original ones have severely decayed in a building. The aim is to recover the original function of the element, to correct design defects or modify the seismic response. In the conservation of historical monuments, repair, when possible, is preferable to substitution.

\section{Enlargement}

It refers to the addition of new material to an already existing member, with adequate connection or interlocking, in order to increase its section and mechanical capacity. Enlargement has been used traditionally to increase the load bearing capacity of walls or to increase the capacity of vaults. Mechanical compatibility requires the use of materials with same stiffness and strength of the original one, and a good connection between the original member and the added material. The removability of the enlargement depends on the possibility of dismantling the added parts without causing significant damage to the original material. Such removal is possible if stone or brick masonry, with limited interlocking, has been used for the enlargement.
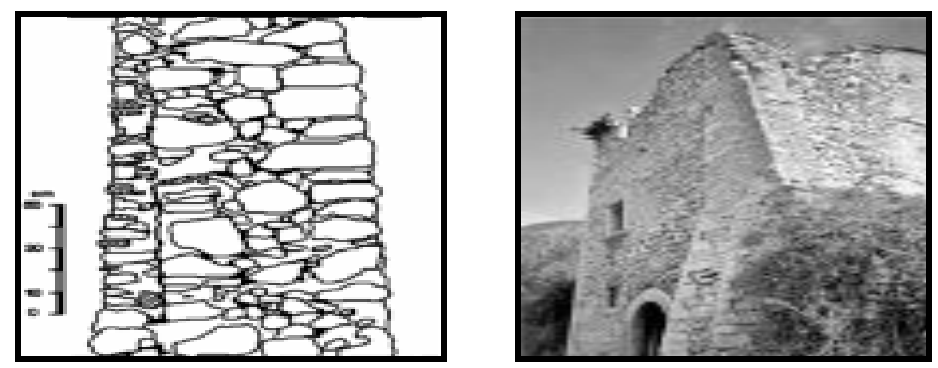

Fig. 3. Grout injection procedure, drilling holes in mortar joints and fixing 


\section{Buttressing}

It is the addition of massive elements made of concrete or masonry to laterally prop a structure. Buttresses resist lateral forces and deformations essentially thanks to their self weight. It contributes to prevent from failure mechanisms related with lateral deformation but if built as a later strengthening device, shows limited efficiency due to lack of satisfactory interlocking or differential settlements from the rest of the structure.

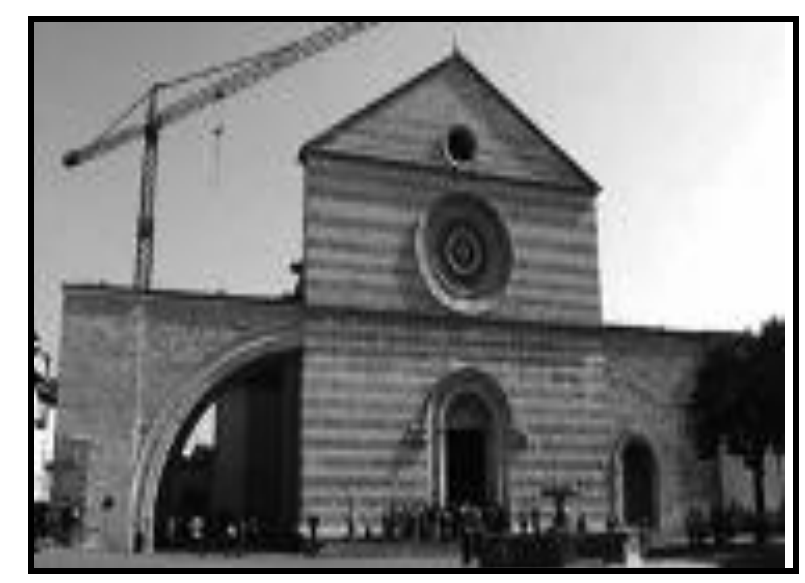

Fig. 4. Buttress at S. Chiara Church in Assisi,

\section{Strutting}

Placing struts between different parts of the structure or between the structure and an external system. Struts are designed to resist a compressive load and are used to laterally prop a structure or structural member. Struts can work in horizontal, vertical or inclined position. Strutting can be used to stabilize damaged structures or elements risking collapse, or not able to carry out their load-bearing function. Inclined struts increase the lateral stiffness of the structure and are used to counteract the out-of-plane forces. Struts can be considered non-invasive and fully reversible.

\subsection{Modern techniques}

\section{Grout Injection of the cracks}

Injection of fluid mortar or other adequate repair materials through cracks or holes previously drilled. The purpose is to fill cracks, existing cavities and internal voids. Injection improves the continuity of masonry and contributes to enhance the average mechanical properties of masonry, using injected materials with compatibility with the original material. Grouting and injection with these materials, is not considered as an "invasive" or "intrusive" technique.
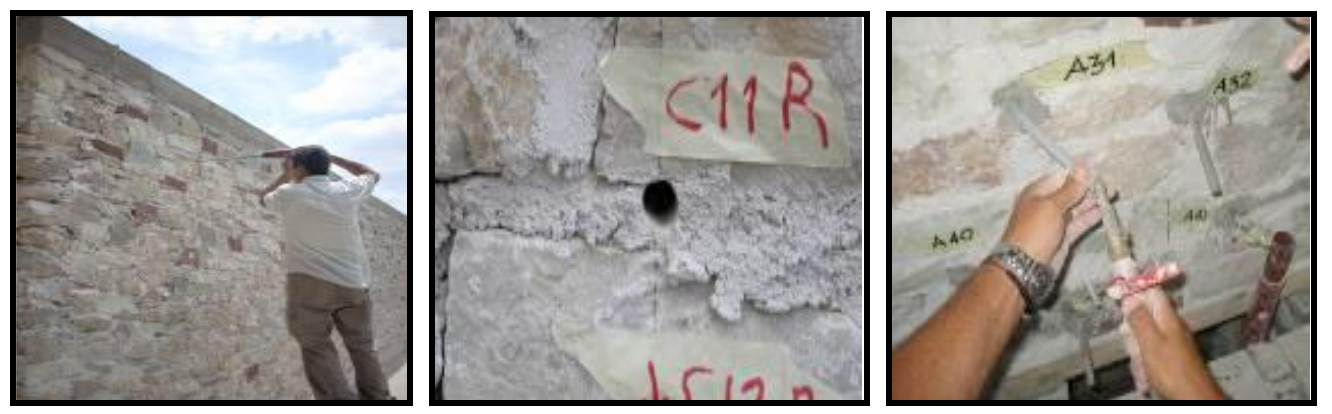

Fig. 5. Grout injection procedure, drilling holes in mortar joints and fixing 
Is an application of high-performance materials on the exterior of existing structures, adequately connected by chemical or physical bonding, or mechanical anchors, to increase their strength capacity and stiffness. The reinforcing material may consists of reinforced concrete jacketing, reinforced plasters, external FRP laminates or sheets, or wood. When concrete or reinforced plasters are used, external reinforcement is normally impossible or very difficult to remove due to the need to connect the original and the added material. The connection is normally obtained with the use of epoxy resins, mortar and fasteners. An effective use of this technique by bonding requires some regularity in the masonry surface.
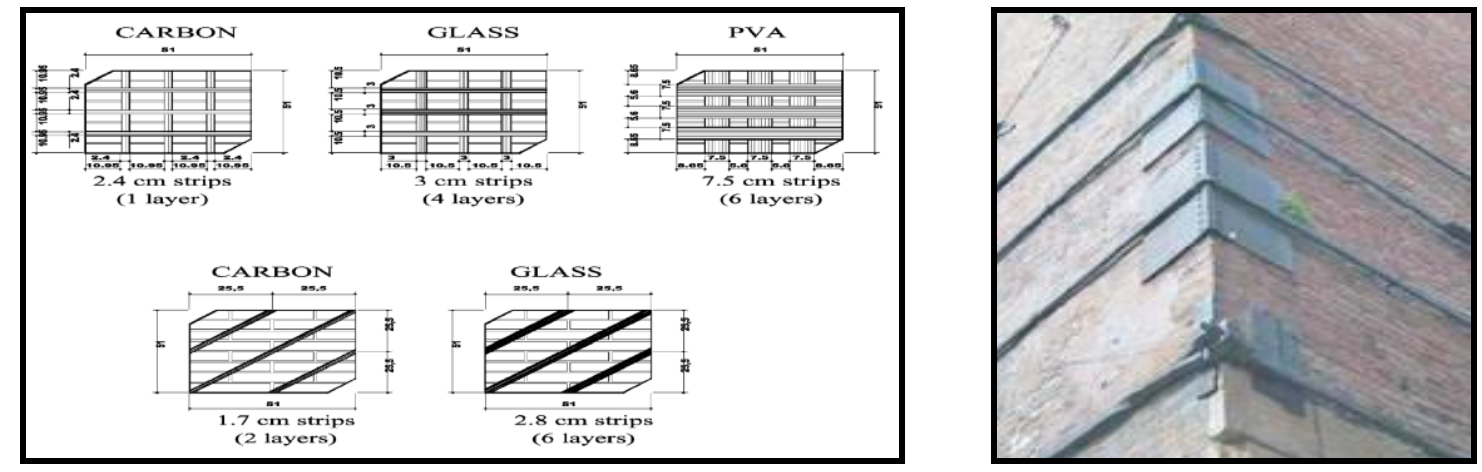

Fig. 6. Single-side or double-side strengthening with FRP strips or steel ties

For seismic strengthening, is necessary to place external reinforcement on opposite sides and to properly connect both sides with ties. Reinforcement enhances the strength and stiffness of the structure by adding a material that can resist tension. In several cases, also ductility can be increased. External reinforcement is normally irreversible, and hardly removable, as removing the added material from the wall will cause the peeling off of the brick or stone surfaces.

\section{Internal reinforcement}

It consists of the insertion of a high-performance material with large tensile strength within perforations produced in the original masonry material. Reinforcement is normally provided by means of steel or FRP bars. Filling the perforations with an adequate mortar is essential in order to provide sufficient bonding between the reinforcing bars and the surrounding material. Internal reinforcement is invasive and non-reversible, as it is impossible to extract the bars after the intervention. Also compatibility and durability problems may arise depending of the type of material used for the reinforcement and the type of mortar. For instance, conventional steel and Portland cement, used in the past for this purpose, may produce significant problems due to limited durability and the corrosion of steel. More recently, stainless steel and titanium are preferred as reinforcing material. Seeking for a better compatibility, hydraulic lime mortar has also been used as injection material in some cases, instead of Portland cement or epoxy resin.

\section{Reinforced injections (stitching)}

Stitching constitutes a particular case of internal reinforcement in which short bars are inserted at different angles from the exterior. Holes are drilled in the element and filled with bars composed of adequate and durable metals (stainless steel, titanium) or FRP's. The holes are injected with fluid mortar or grout. Stitching acts by improving or reinforcing the material or structural member, or by tying different parts together. Reinforced injections will cause some deterioration to the wall or stone in which the drilling is executed and, in principle, should not be applied when the walls or stones with artistic paintings or decorations. The use of Portland cement grout is not incompatible with the surrounding masonry. Epoxy resin may also generate some severe compatibility problems. Reinforced injections constitute a full invasive and irreversible technique because removing the injected materials is not possible. Stitching, while improving the overall strength and ductility of the structure, may also increase the cracking and damaging in the stones or bricks due to soil settlements, earthquakes or other actions. Without reinforced injections, cracks will develop along mortar-unit interfaces and mortar joints and will not affect the bricks or stone blocks, and thus cause less significant and more easily reparable damage. This type of cracks is, in principle, not difficult to repair.

Once strengthened with reinforced injections, damage will develop across the bricks and stone blocks, showing numerous thin cracks instead of a single or few individual cracks and much more difficult to repair. In short, 
reinforced injections may alter the resisting nature of the structure, the type of expected damage, and its reparability.

\section{Reinforced re-pointing}

Combines traditional re-pointing with the inclusion of reinforcing bars, normally made of ductile and durable metals or FRP's. Reinforced re-pointing increases the compressive and shear strength in small thickness masonry. It is normally more effective as a way of reducing the deformation. It has also a confining effect on the walls, may be used to improve the connection between parts and may provide additional ductility.
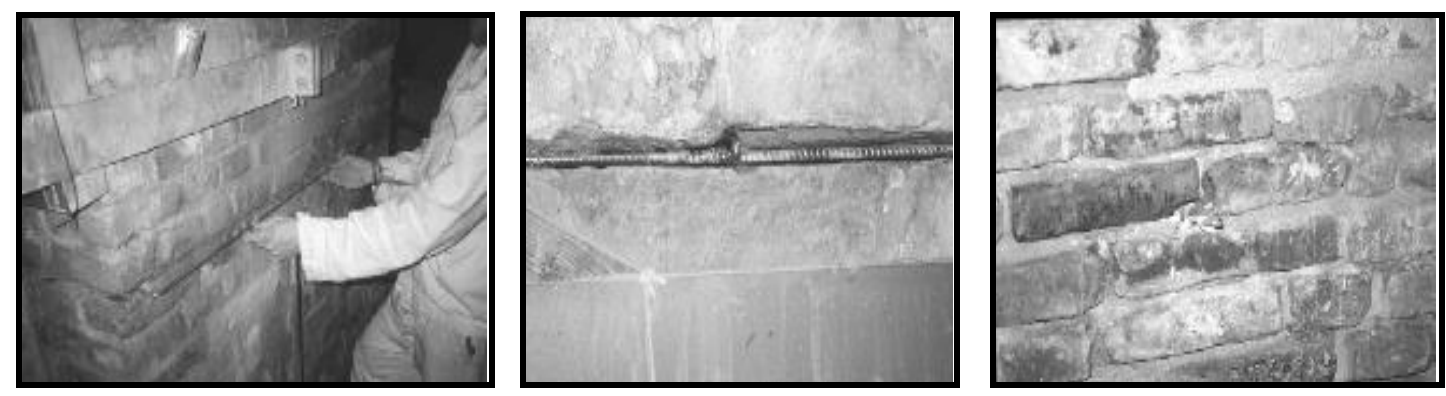

Fig. 7. Execution stages in the case of reinforced re-pointing performed

Reinforced re-pointing is indicated for masonry walls with regular horizontal joints. It is usually applied in combination with other interventions and can be considered only moderately invasive and mostly removable, as in many cases removing again the mortar and even the bar from the joints will be possible. Adequate durability of the reinforcement (especially when using metals), as well as adequate mechanical connection, require the placement of the bars at sufficient depth within the joint.

\section{Jacketing}

It is based on the application of an outer covering of high-performance material around an existing structural element. It is applied to stabilize damaged members working in compression (such as pillars and piers), or to strengthen elements subjected to high compressive stresses, members showing excessive lateral deformation or formed by parts poorly connected. The target is at producing continuous confinement and improving the strength and stiffness of the material.

Jacketing may be fully non-invasive and removable, but is obtrusive since it hides the original masonry behind the new material. Providing connection between the covering and the original material with generate a reinforcing or enlarging effect. In this case, jacketing can be hardly removable, while compatibility problems may appear when the confinement material is much stiffer than the original one, or because of the creation of an external water-proof barrier preventing the natural perspiration of the original masonry or stone.
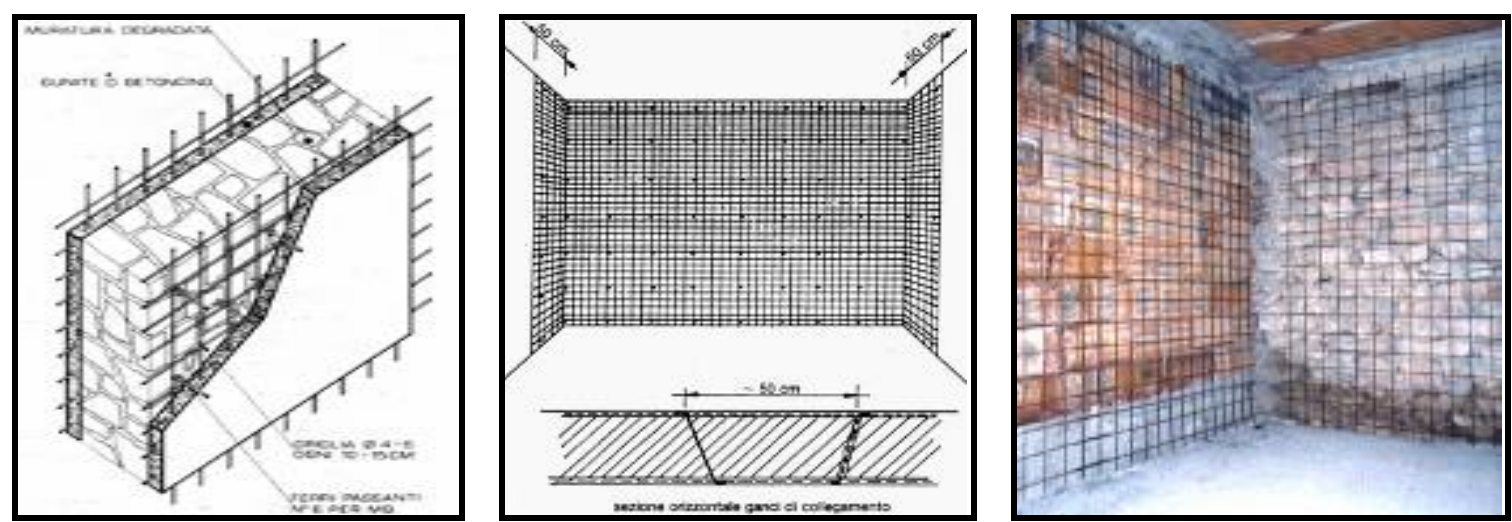

Fig. 8. R.C. jacketing reinforcing

\section{Pre-stressing}

Pre-stressing by means of steel or FRP bars provides many applications for the repair or strengthening of masonry structures. Due to its versatility, it gives non-invasive, removable and mechanically compatible solutions. Providing an initial state of 
compressive stresses will, in many cases, increase the capacity of the masonry members to resist flexural and tensile forces, including those induced by earthquakes. Pre-stressing by means of bars or strands can be also used to improve confinement or tying effects by introducing an active action. By providing some initial pre-stressing force, ties and confinement rings will generate an stabilizing force against the structure or the further deformation. Another application can be found in the generation of frictional contacts and connections. Providing compressive stresses perpendicular to the contact surfaces (among different parts, or cracked members) generates significant friction and prevents from relative sliding. Generating frictional forces across different members can be used as a way to mechanically tie the two parts in shear. A frictional union can be generated by pre-stressing bars or tendons, externally applied and adequately anchored in the two parts.

\section{Dismantling and reassembling}

Consists on the complete dismantling of an element or a structure to repair, extract or substitute part of the components, and then rebuilding it accurately according the original organization and shape. The purpose is to recover the functionality of a structure while maintaining its historical and cultural value. Dismantling and reassembling has been used for repair and restoration, as for instance when there are problems caused by the corrosion of iron or steel used in the masonry or stones.
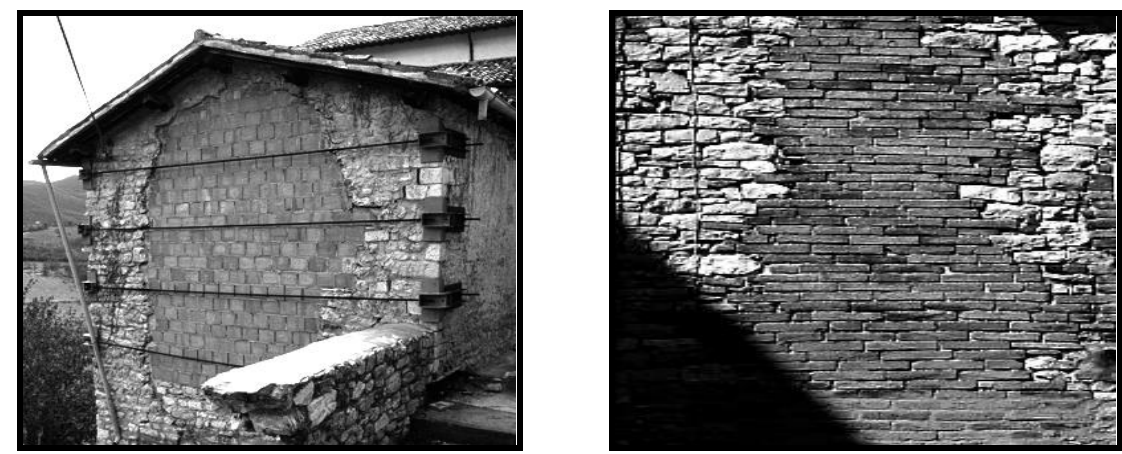

Fig. 9. Masonry replacement intervention

\section{Secondary structures}

In some cases, existing masonry structures have been strengthened by building a secondary reinforced concrete or steel structure, connected to them and aimed at provide additional strength and stiffness. Accurate and realistic structural analyses are necessary because of potential mechanical incompatibility problems. A stiffer secondary structure (for instance, a new concrete frame) will tend to attract more loads, and may eventually become the only part actually resisting either the vertical or horizontal actions. Instead, a flexible steel frame will provide resistance only after the masonry has cracked. An extreme variant is found in the functional substitution of the structure, consisting of the creation of a new structure intended to take entirely the resisting role, while the original one preserves its historical and aesthetical values

\section{Results and Discussion}

A summary of repair techniques for masonry and earthen structures with respective advantages and disadvantages is presented in the following table.

\begin{tabular}{|c|c|c|c|}
\hline & Considerations & $\overline{\text { Pro }}$ & Con \\
\hline 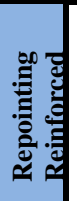 & $\begin{array}{l}\text { Compatibility of mortar with original } \\
\text { mortar and unit.Deep removal of external } \\
\text { deteriorated mortar is necessary } \\
\text { Size and corrosion resistance of } \\
\text { reinforcing bars } \\
\text { Use of sacrificial mortar }\end{array}$ & $\begin{array}{l}\text { Increase in strength of masonry component } \\
\text { Effective in prevention of water penetration } \\
\text { through joints } \\
\text { Confining effect in the masonry component } \\
\text { in reinf. Repointing.Can be reversible } \\
\text { depending on the mortar used. }\end{array}$ & $\begin{array}{l}\text { May accelerate the decay of masonry units } \\
\text { unless the mortar is compatible } \\
\text { May not be effective in irregular } \\
\text { May lead corrosion if not proper } \\
\text { reinforcing bars and enough cover is } \\
\text { provided }\end{array}$ \\
\hline 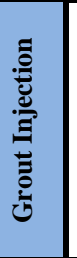 & $\begin{array}{l}\text { Compatibility of injected material with } \\
\text { original mortar and unit } \\
\text { Suitability of wall section for injection } \\
\text { Suitability of wall section for and } \\
\text { preparation of masonry for injection } \\
\text { Determination of specific locations for } \\
\text { grouting }\end{array}$ & $\begin{array}{l}\text { Can restore the uniformity homogeneity of } \\
\text { strength in section } \\
\text { Effective in prevention of water penetration } \\
\text { through cracks and voids } \\
\text { Can restore the continuity of multi leaf wall } \\
\text { sections as a result increasing the strength } \\
\text { of the element }\end{array}$ & $\begin{array}{l}\text { Irreversible action } \\
\text { Not suitable for walls with low percentage } \\
\text { of voids and loose infill } \\
\text { Grout may cause segregation and } \\
\text { shrinkage } \\
\text { May not be effective due to lack of precise } \\
\text { knowledge on the distribution of voids } \\
\text { and their sizes }\end{array}$ \\
\hline
\end{tabular}




\begin{tabular}{|c|c|c|c|}
\hline 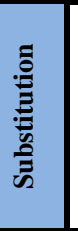 & $\begin{array}{l}\text { Differentiable from the original fabric but } \\
\text { not obtrusive } \\
\text { Compatibility of new material with the } \\
\text { original material } \\
\text { Preferred after all methods proved to be } \\
\text { ineffective }\end{array}$ & $\begin{array}{l}\text { Recover the original function of structural } \\
\text { element } \\
\text { Increase the stability and integrity of the } \\
\text { structure } \\
\text { Improve the global behavior of the structure } \\
\text { Might be reversible depending on the size } \\
\text { of substitution }\end{array}$ & $\begin{array}{l}\text { Mostly irreversible } \\
\text { Obtrusive especially when the structural } \\
\text { system is substituted } \\
\text { May violate the minimum intervention } \\
\text { principle }\end{array}$ \\
\hline : & $\begin{array}{l}\text { Compatibility of material used for } \\
\text { stitching with original material } \\
\text { Preferred after other methods like tying, } \\
\text { grouting, confinement, anchoring etc } \\
\text { proved to be ineffective }\end{array}$ & $\begin{array}{l}\text { Improve the connections of adjacent walls } \\
\text { Add extra strength and ductility to the wall } \\
\text { Can control the crack propagation }\end{array}$ & $\begin{array}{l}\text { Might be reversible by harming the } \\
\text { original fabric.Can be obtrusive } \\
\text { depending on the type shape of material } \\
\text { used } \\
\text { May need intense intervention for the } \\
\text { placement of plates etc }\end{array}$ \\
\hline$\stackrel{\infty}{\sum_{\epsilon}^{\infty}}$ & $\begin{array}{l}\text { Compatibility of material used for tying } \\
\text { with original material } \\
\text { May necessitate anchorage }\end{array}$ & $\begin{array}{l}\text { Effective in compensating the weakness of } \\
\text { masonry in tension } \\
\text { Generally necessitate minor alteration } \\
\text { /reversible } \\
\text { Can ensure stability and integrity of the } \\
\text { element }\end{array}$ & $\begin{array}{l}\text { May lead corrosion problems if tying bars } \\
\text { not selected properly } \\
\text { May be obtrusive in some cases }\end{array}$ \\
\hline 己ेँ & $\begin{array}{l}\text { Compatibility of confining material with } \\
\text { original material } \\
\text { Determination of locations for confining } \\
\text { rings/bars/ties }\end{array}$ & $\begin{array}{l}\text { Effective in increasing the capacity of } \\
\text { structural element it is applied } \\
\text { Effective in prevention of separation of } \\
\text { external leaves in multi-leaf walls } \\
\text { Improve the stability and stiffness is } \\
\text { confined.Can be reversible }\end{array}$ & $\begin{array}{l}\text { Depending on the material used it can be } \\
\text { obtrusive } \\
\text { May lead deterioration problems if not } \\
\text { protected against/selected accordingly } \\
\text { when exposed to environmental effects }\end{array}$ \\
\hline 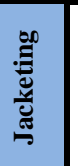 & $\begin{array}{l}\text { Transversal connections of jackets and } \\
\text { masonry walls } \\
\text { Bonding between nets and masonry walls } \\
\text { Compatibility of new material with the old } \\
\text { one }\end{array}$ & $\begin{array}{l}\text { Increase strength and ductility of the wall } \\
\text { Improve the global behavior of the structure }\end{array}$ & $\begin{array}{l}\text { Irreversible and highly invasive } \\
\text { May lead eccentricity under dynamic } \\
\text { loading since it increases stiffness at } \\
\text { particular element where applied }\end{array}$ \\
\hline 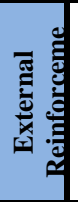 & $\begin{array}{l}\text { Location of application } \\
\text { Determination of reinforcing material } \\
\text { Compatibility of material with the original } \\
\text { material }\end{array}$ & $\begin{array}{l}\text { Increase strength and ductility of the wall } \\
\text { Improve the global behavior of the structure } \\
\text { Can be effectively used in curved elements, } \\
\text { walls etc } \\
\text { Can be reversible depending on the } \\
\text { materials used }\end{array}$ & $\begin{array}{l}\text { Heat and radiation sensitivity of FRPs } \\
\text { Loosening of the bond due to moisture for } \\
\text { FRP strengthening } \\
\text { Might be obtrusive depending on the } \\
\text { material used }\end{array}$ \\
\hline 递当 & Location and type of anchoring & $\begin{array}{l}\text { Can increase the stability of structure or } \\
\text { element } \\
\text { Can be non obtrusive depending on the } \\
\text { place of application }\end{array}$ & $\begin{array}{l}\text { May be invasive the historic fabric } \\
\text { May change the appearance especially } \\
\text { when applied externally }\end{array}$ \\
\hline 递 & $\begin{array}{l}\text { Amount of compression applied to the } \\
\text { member or structure } \\
\text { Stability of anchorages at the ends }\end{array}$ & $\begin{array}{l}\text { Increase the capacity of member } \\
\text { Improve the global behavior and integrity } \\
\text { Can be applied externally and internally on } \\
\text { element or structural level }\end{array}$ & May lose the effectiveness in time \\
\hline 吾 & $\begin{array}{l}\text { Location of application } \\
\text { Connection of new construction with the } \\
\text { old part }\end{array}$ & $\begin{array}{l}\text { Increase the stiffness and integrity of the } \\
\text { structure } \\
\text { Improve the global behavior } \\
\text { Confine the structure horizontally } \\
\text { Relieve stresses in certain places }\end{array}$ & $\begin{array}{l}\text { Alteration in appearance } \\
\text { Might not be reversible depending on size } \\
\text { Might not be reversible depending on size }\end{array}$ \\
\hline 吾当 & Selection of strutting & $\begin{array}{l}\text { Can provide an immediate and reliable } \\
\text { supporting } \\
\text { Can be easily replaced }\end{array}$ & $\begin{array}{l}\text { Mainly temporary solution } \\
\text { Not improve but maintain the current } \\
\text { condition of structure }\end{array}$ \\
\hline
\end{tabular}

Table 1. Strengthening methods with their advantages and limits

\section{Conclusions}

The general overview of the main repair techniques shows several criticisms in the decision process, but also guidelines which could help in the choice. The most of research is mainly based on the study of mechanical aspects of the techniques, and not on procedures and possible problems, the durability, the maintenance aspects, the etc. Up to now, the following aspects are not yet considered:

- Maintenance suggestions and periodic controls/monitoring;

- Long term performance / durability;

- Life time;

- Standards and recommendations;

- Laboratory controls and on site controls; 
- Control parameters of the effectiveness of the intervention;

- Analytic procedures and structural modeling.

In case of interventions, the implications of ductile behavior in terms of conservation of the structures are not clearly evidenced. It is noted that "good" ductile performance means that large deformations and very severe damage occur, not only in the new added materials and components, but also in the original materials and components to which they are structurally connected. This usually corresponds to loss of historic and artistic value and even loss of any residual life after the earthquake.

Some intervention techniques lead to significant modification of the original structural behavior. Even though those intervention techniques may be considered "in principle correct", as they contribute to significant resistance improvement and redistribution of seismic loads and ductility, due to the limitations related with the theoretical/numerical models, the real behavior of the strengthened structures cannot be accurately predicted. As a result, some intervention techniques of this type may represent a severe change for the structures (the effect of substituting floors and roofs with reinforced concrete slabs).

\section{References}

1. Avorio A., Borri A., Corradi M. (2002). Ricerche per la ricostruzione. Iniziative di carattere tecnico e scientifico a supporto della ricostruzione, Regione Umbria, DEI, Rome, Italy.

2. Baronio G., Binda L., Modena C. (1992). Criteria and methods for the optimal choice of grouts according to the characteristics of masonries. Workshop CNR-GNDT "Effectiveness of injection techniques for retrofitting of stone and brick masonry walls in seismic areas", editor L. Binda, 30-31 March, pp. 139-157.

3. Binda L., Baronio G., Tiraboschi C. (1993a). Repair of brick-masonries by injection of grouts: experimental research. Journal of Structural Engineering, Madras, India, Vol. 20, No.1, pp. 29-44.

4. Binda L., Modena C., Baronio G., Abbaneo S., (1997) Repair and investigation techniques for stone masonry walls, Construction and Building Materials, Vol. 11, N. 3, pp. 133-142.

5. Borri A., De Maria A. (2009). EuroCode 8 and Italian code. A comparison about safety levels and classification of interventions on masonry existing buildings. EuroCode 8 Perspectives from the Italian Standpoint Workshop, pp. 237246.

6. Carocci C. (2001). Guidelines for the safety and preservation of historical centers in seismic area. III International Seminar on Structural Analysis of Historical Constructions - SAHC, Guimarães, Portugal, 7-9 November, pp. 145-165.

7. Foraboschi P. (2005). Consolidamento statico e adeguamento sismico. Annotazioni per le costruzioni in muratura. L'Edilizia, No. 138.

8. Modena C., Zavarise G., Valluzzi M.R. (1997b). Modeling of stone masonry walls strengthened by r.c. jackets. IV International Symposium On Computer Methods in Structural Masonry - STRUMAS, Florence, Italy, pp. 285-292.

9. Tomaževič M. (1999). Earthquake resistant design of masonry buildings. Imperial College Press, London, UK.

10. Valluzzi M.R., Disarò M., Modena C. (2003a). Bed joints reinforcement of masonry panels with frp bars. International Conference on Composites in Construction, Rende (CS), Italy, 16-19 September, pp. 427-432. 